https://doi.org/10.32541/recie.2017.v1i1.pp83-85

\title{
COMENTARIO DE “APRENDER E INSTRUIR EN LOS ANDES SIGLOS XV Y XVI” DE ENRIQUE GONZÁLEZ CARRÉ Y FERMÍN DEL PINO-DÍAZ, TOMO I. COLECCIÓN PENSAMIENTO EDUCATIVO PERUANO, VOL. 3. LIMA: DERRAMA MAGISTERIAL, 2013
}

\section{- María Filomena González Canalda \\ Correo-e: mariafilomenagonzalezcanalda@gmail.com}

Este es el primer volumen de la colección Pensamiento Educativo Peruano ${ }^{1}$ de la Editora Derrama Magisterial. Al igual que los otros volúmenes incluye uno o varios estudios sobre el pensamiento educativo del período, que trata una selección de textos y documentos.

Este volumen contiene el trabajo "Aprender en el Tawantinsuyo" de Enrique González Carré y "Propuesta Educativa para el Perú del padre Joseph de Acosta”, por Fermín del Pino-Díaz.

Lo primero que notamos en estos volúmenes es el cuidado de la edición, lo didáctico de los trabajos presentados y lo pertinente de la selección de textos y documentos. Además de las ilustraciones apropiadas en el ensayo "Aprender en el Tawantinsuyo".

El trabajo de Enrique González Carré comienza por definir la relación entre cultura y educación, señalando que esta última es un "proceso permanente de socialización y endoculturación mediante el cual el individuo conoce, aprende y hace uso de su cultura en todos los aspectos de su vida" 2 , tanto en la educación escolarizada como la no escolarizada. Enfatiza que es el "proceso de socialización o endoculturación el más importante en la transmisión y difusión de la cultura en el Perú”3, y agregaría que en todas las culturas, pero que no es reconocido como tal.

Explica las características del área cultural andina, dentro de la cual se encuentra el Perú actual, y donde los seres humanos se establecieron desde hace 12 mil años creando y recreando cultura. Hace una breve introducción a la socialización preincaica, pero se detiene en la educación en el Tawantinsuyo, resaltando las fuentes que se tienen a mano en la actualidad para investigar el período.

La educación en el Tawantinsuyo la divide en dos partes: la educación general y popular, donde explica las características de cada uno de los ritos de pasaje; Rutuchicuy (de los 6 a los 12 años), Quicochicuy (adolescencia de las jóvenes), del Warachicuy (para los varones cerca de los 18 años), del matrimonio y la muerte; y, la educación estatal de la nobleza: en el Yachaywasio (Casa del Saber) para hombres, y el Acllawasio (Casa de las Escogidas) para mujeres.

1 Esta colección consta de 15 tomos y abarca el pensamiento educativo del Perú desde la época pre-hispánica hasta nuestros días.

2 "Aprender e Instruir en los Andes Siglos XV y XVI" de Enrique González Carré y Fermín del Pino-Díaz. Colección Pensamiento Educativo Peruano. Volumen 1. Derrama Magisterial. S/F. Pg. 3.

3 Ibídem.

ISSN (impreso): 2636-2139

ISSN (en línea): 2636-2147

Sitio web: https://revistas.isfodosu.edu.do/recie

\section{COMO CITAR:}

González Canalda, M. F. (2017). Comentario de "Aprender e instruir en los Andes siglos XV y XVI" de Enrique González Carré y Fermín del Pino-Díaz, Tomo I. Colección Pensamiento Educativo Peruano, Vol. 3. Lima: Derrama Magisterial, 2013. Revista Caribeña de Investigación Educativa (RECIE), 1(1), 83-85. https://doi.org/10.32541/ recie.2017.v1i1.pp83-85 
La educación general y popular se impartía en todos los grupos y duraba toda la vida. Era responsabilidad de la familia y el ayllu. Se definía por la maduración fisiológica y social, mediante la cual, se transmitían "ideas, conocimientos, habilidades, dominio de técnicas...y... la práctica de una conducta social según la edad de la persona y con arreglos a los principios y valores de la sociedad inca." ${ }^{4}$ Dependiendo del grupo al que pertenecían se entrenaba a las personas en las labores propias de este.

En la educación para la nobleza, una educación institucionalizada, explica las características del Yachaywasio y el Acllawasio. Según el sexo se determinaba el tipo de educación a recibir: educación para gobernar o educación para atender a la nobleza, el culto religioso, la producción de tejidos y ser esposas o concubinas de nobles funcionarios.

Había solamente un Yachaywasi en el Tawantinsuyu ubicado en el Cusco, donde los jóvenes nobles de todo el imperio acudían. La educación en el Yachaywasi duraba más de 4 años, y a él asistían, como se ha dicho todos los nobles regionales, no solamente los de linaje inca. Estaba dirigido por un maestro o amauta, verdadero sabio del conocimiento acumulado por la sociedad inca.

El Acllawasi o Casa de las Escogidas estaba dirigido a todas las jóvenes consideradas bellas aun no fueran de la nobleza. Estas casas, a diferencia del Yachaywasi, estaban repartidas en todo el territorio del Tawantinsuyu. El autor recalca que el Acllawasi no era únicamente el lugar para las "vírgenes del sol”, sino que las mujeres allí cumplían una función económica importante, como es el caso de las tejedoras, a pesar de la situación de dominio y sumisión a la cual estaban sometidas las mujeres durante el período inca.

Por último, el autor destaca el gran desarrollo del conocimiento en la Sociedad Inca que incluía técnicas quirúrgicas, conocimientos botánicos anatómicos, fisiológicos; además, de las técnicas constructivas que implicaban conocimientos de topografía, geología, geometría y física ${ }^{5}$. Sin olvidar la enseñanza del lenguaje de los quipus, la música y la literatura lo que supuso, según sus propias palabras, que para su pleno dominio había que educar a las personas.

En el segundo trabajo presentado en este primer volumen, "Propuesta Educativa para el Perú del padre Joseph de Acosta", su autor, Fermín del Pino Díaz, inicia este ensayo analizando las características del humanismo europeo y su relación con los jesuitas. Destaca el papel del padre De Acosta, entre 1571 y su salida para México en 1582, en la fundación de colegios tanto para españoles como para criollos y mestizos, fiel a la tarea pedagógica de los jesuitas.

El padre Joseph de Acosta enseńó en el colegio jesuita de San Pablo, en Lima, y en la Universidad de San Marcos. Colaboró en los centros misionales de Juli, Cercado y Cusco y el colegio de San Martín dedicado a instruir criollos.

El padre Joseph fue, además autor de la "Historia Natural y Moral de las Indias" (1590) donde según del Pino-Díaz, destaca el "método misional apostólico basado en la tolerancia cultural." ${ }^{3}$ Fermín del Pino-Díaz polemiza con otros investigadores sobre la intención "imperialista" de la obra del padre Joseph de Acosta. Sostiene que De Acosta tenía una actitud tolerante a favor de mestizos e indios, ya que apoyaba la inclusión de mestizos como sacerdotes y la admisión de estos e indios nobles a los colegios jesuitas, así como la traducción del catecismo a lenguas vernáculas. Indirectamente,

4 Ibídem, p. 14.

5 Ibídem, p. 23.

6 Ibídem, p. 140. 
era una manera de adoctrinar, método que luego se conocería como "autonomista” en las misiones del Paraguay. De Acosta sostenía que el método misional adecuado era el de tolerar e incorporar "ritos" de las culturas, donde se hacía el trabajo evangelizador que no estuvieran en conflicto con las católicas. Es importante destacar que en ese momento de sometimiento colonial de los pueblos americanos, Para el sacerdote, y contrario al pensamiento de la época, las creencias de los pueblos autóctonos eran su religión, no idolatrías. Este es quizá el pensamiento más avanzado de la época con relación a las culturas del nuevo continente.

Del Pino-Díaz sostiene que el padre Joseph de Acosta provenía de una familia de "cristianos nuevos", posiblemente por parte de su madre ${ }^{7}$. Considera que por esa razón asumió la defensa de indios y mestizos, ya que en palabras del autor, "Es normal que estos miembros selectos de minorías culturales, cuestionadas internamente, asuman intelectualmente la defensa de las minorías culturales externas."

Para Del Pino-Díaz lo más importante de la labor del padre fue la utilización de una metodología educativa que él considera la mejor para la juventud. Esta se basaba en la libre competencia de los jóvenes, donde estos aprendían "enseñando a otros y desarrollando en esta praxis interactiva la propia capacidad especial de cada uno." Este método se oponía al de "coro y retiro" de otras órdenes religiosas como la de los dominicos, franciscanos, agustinos y mercedario (entendiendo "coro" como repetición colectiva de lecturas).

El autor plantea que una parte de esta práctica pedagógica utilizada por el De Acosta en Perú fue rescatada a finales del Siglo xix por la "Institución Libre de Enseńanza”, creada en 1876 en España. Afirma que las ideas renovadoras en el campo de la educación “... fueron concebidas en el Perú por el padre Acosta al tratar de entender su compleja naturaleza climática y territorial." ${ }^{0}$

Por último, enfatiza que la labor del sacerdote Acosta debe ser objeto de una investigación más profunda que permita la valoración de todos sus aportes, no solamente en la educación sino en otros campos como la historia, la antropología y la política.

7 Ibídem, p. 125.

8 Ibídem, p. 125.

9 Ibídem, p. 151.

10 Ibídem, p. 152. 